\title{
THE PLAGUE OF MARSEILLES AND THE EXPERIMENTS OF PROFESSOR ANTON DEIDIER ON ITS TRANSMISSION
}

\author{
by
}

\author{
RAYMOND WILLIAMSON, M.A., B.SG., M.D. \\ Reader in Morbid Histology in the University of Cambridge
}

\begin{abstract}
The conduct of some physicians in France in the years 1720 and 1721 affords remarkable instances of the power of prepossession in favour of an hypothesis.

RUSSELL ${ }^{1}$
\end{abstract}

THE story of the Plague of Marseilles in I720-I has been vividly described by Gaffarel and Duranty ${ }^{2}$ and the part played by the administration, the faculty of medicine, the Church, the port officials and other public bodies has been carefully and sympathetically assessed. There are, however, many aspects of this epidemic which deserve further consideration. One is the research of Professor Anton Deidier into the cause of plague. Although his reasons for performing the experiments which will be described later seem strange to us, and although some of the conclusions he drew were inaccurate, the experiments he made are worth recalling. He transmitted plague by injecting bile from plague corpses into dogs; he showed that the bile of dogs dying of plague produced plague in other dogs, and he showed that the bile of persons dying of other fevers did not produce plague. We now know that the bile in plague contains Pasteurella pestis. ${ }^{3}$

Most of the physicians of Marseilles, who attended the first victims of the epidemic, were of the opinion that the disease was plague and that it was contagious:

But nothing could subdue the infatuated incredulity of some persons; and, spite of the impetuosity with which they saw the contagion daily spread in the city, they still would persist in not believing it the plague. The échevins had given so unfavourable an impression to the Court, of the physicians of Marseilles, that no confidence was placed in their reports; and Messrs. Chycoineau and Verny, physicians of Montpellier, were deputed to visit Marseilles, and examine into the nature of the disease that raged there. They arrived accordingly on the 12th of August, with Mons. Soulliers, one of the principal surgeons of the same university ... and everyone hoped from them such a decision as should favour their own incredulity."

The Montpellier party consulted with the physicians of the city, visited the sick at the hospital and a few in their homes and had three post-mortem examinations made in their presence. They then met the échevins in private, and the following statement was published in the city: 


\section{Raymond Williamson}

\section{ADVICE TO THE PUBLIC}

On the report made to the governor and échevins of the city by the physicians from Montpellier, they have thought it their duty to advertise the public, that the malady which now reigns here is not pestilential, but only a common malignant fever, the progress of which, it is hoped, will speedily be stopped, by separating those who are suspected of being diseased from those in perfect health, and by certain other regulations which will immediately be established. ${ }^{5}$

In a report which the Montpellier physicians sent to the Court of France they stated:

The malady which now reigns in this city is a true pestilential fever, not yet arrived at its utmost degree of malignity.

and they referred to it as a 'sort of plague'. ${ }^{6}$

Messrs. Chicoyneau, Verny and Soullier had been sent to Marseilles on the advice of Monsieur Chirac, the King's physician. When he received their report he sent a memoir to the Marseilles physicians in which he said:

All things well considered, and after having examined with the greatest attention the different reports sent from Marseilles ... I have judged that the malady, though great in itself, and extremely dangerous, is only a common malignant fever such as I saw myself reign there in the years 1709 and 1710 , and by no means the plague brought from the Levant. . . The unwholesome food of the lower class of people in that town is quite sufficient to produce such an effect.?

Not only did he give his opinion that the physicians and surgeons of the city of Marseilles were wrong in believing the disease to be plague brought from the Levant in Captain Chataud's vessel but he cast unjustifiable aspersions on their conduct.

After reporting on the epidemic Messrs. Chicoyneau, Verny and Soullier went to Aix, where they were residing in a country house keeping quarantine before returning to Montpellier, when, because the state of Marseilles was becoming desperate, and medical help was sorely needed, the King ordered Professor Deidier and the master surgeon Monsieur Fiobesse to join them and issued instructions that they should all proceed to Marseilles and give what help they could. They arrived at Marseilles on 17 September, and another party of physicians joined them a few days later.

The epidemic was at its height and prodigious efforts were being made to clear the streets of the dead and dying and to open new hospitals. In a letter to Monsieur Maugue, Professor Deidier said:

I can scarcely describe the frightful disorder which I found in this desolated town. On entering by the Gate of Aix with Messieurs Chicoyneau and Verny, the sight up to the Gate of Rome was the most hideous in the world, all the doors and windows of the houses were closed, the pavement was covered from one side to the other with the sick and the dying, lying on their mattrasses without any succour; in the middle of the streets and in the squares one saw nothing but half rotting corpses and old clothes lying in the mud, and the plague carts led by convicts carrying away the dead. 


\section{The Plague of Marseilles}

The day after our arrival, M. de Soissans, Aide de Camp de M. le Commandant, took us to the Jeu de Mail and the Charité, where they had arranged to erect two hospitals: we then went through the town from one end to the other. It was not possible to put a foot anywhere without stepping on the dead or on the beds of the sick. ${ }^{8}$

Immediately after their arrival the Montpellier physicians made very great demands on the échevins to ensure their personal comfort and well-being while in Marseilles and were troublesome to such a degree that when the epidemic died down the échevins were glad to see them depart. On the other hand, the physicians soon began to organize a medical service and treated the sick in their homes and in the streets, and their conduct in this respect is beyond praise. Their attitude towards the sick reflected the opinion they had expressed to the échevins that the disease was not pestilential.

Monsieur Pichatty de Croissante who was secretary to the four échevins during the plague says in his Journal of the Plague at Marseilles:

The Plague had till then been treated as the Plague, the Sick presently judged of the Danger of their Sickness by the Behaviour of the Physicians who visited them: M. de Chicoyneau, Chancellor of the University of Montpellier, M. Verny, and M. Deidier, give them Reason to believe, on the contrary, that 'tis of all Distempers the least dangerous and the most common: they approach them without the least Concern or Mark of Emotion, without Repugnance, without Precaution; they even sit down upon their Beds, touch their Buboes and Sores, and stay by them calmly as long as is necessary to inform themselves of the State of their Case, the Symptoms of their Distemper, and to see the Surgeons perform the Operations they order: They go every where, and pass through all the Quarters, they examine the Sick, in the Streets, in the publick Places, in the Houses, and in the Hospitals; one would think them invulnerable, or tutular Angels sent by God to save every poor Creature's Life; they refuse the Money the Rich offer them: nor receive anything from anybody, but a thousand Blessings from all; their Manner of proceeding, with the Reputation of their Names, recover the Sick by the Hopes and Confidence they raise in them. ${ }^{\circ}$

The report of Chicoyneau, Verny and Soullier to the Regent suggests that even on their first visit there was some doubt in their minds when they said the disease was not contagious. Bertrand says it was more marked:

When they returned afterwards to Marseilles to attend upon the sick. Struck with the state in which they found them, with the similarity of the disease in all the persons attacked, with its resistance to all their remedies, with the numbers that fell victims to it, with the death of their own servants and even of some of the surgeons who had accompanied them, they spoke loudly of the contagion, and even showed that they feared it not a little. Not that they can be accused of having been sparing of their persons; on the contrary, it is but justice due to them to own that they uniformly approached the sick with the utmost firmness, yet it was not without great precautions, and evident apprehension of danger. ${ }^{10}$

On 4 October a hospital erected of timber and sailcloth in the Grand Mail, a square on the outskirts of the city, was ready to receive patients, as was the neighbouring Charité, which had been converted into a hospital. The opening of these brought great relief to the inhabitants, and the sick 


\section{Raymond Williamson}

creep thither from all Quarters. A number of Galley-slaves are employed to fetch those who cannot help themselves, and are lying in the publick Streets, and in the Houses. ${ }^{11}$

Towards the end of October and during November the epidemic began to die down, and Bertrand says that having happily escaped the plague the Montpellier physicians

began again to waver in their opinions. Emboldened by the evident diminution of the malady, which became every day more and more palpable, they as loudly denied the contagion as they had before confessed it, - nay, they even in some sort insulted the timidity of those who feared it, forgetting that they themselves had been of that number. ${ }^{12}$

This great catastrophe failed to unite the physicians, all of whom were working heroically to combat it. Not only was there resentment on the part of the Marseilles physicians because of Chirac's tactless letter and the superior airs of the Montpellier and other foreign physicians, but they were divided in their views about the nature and origin of plague. The Marseilles physicians were contagionists, the foreign physicians, most of whom were Chirac's pupils, were anti-contagionists. Bertrand, who was the chief spokesman of the Marseilles Faculty, said:

But,-who will believe it?-that twelve physicians were assembled together in one city for the treatment of the same disease, with which so many thousands were afflicted without ever deigning to meet together and confer on its nature, so as to find, if not the true cause of it, at least some remedy which might prove efficacious against its ravages, or to consult upon the best method of treating it? On the contrary, they always kept themselves divided into different bands, forming as it were different sects. The public were so much the more scandalized at this division, as they had seen, in the beginning of the contagion, the physicians of the city assemble every evening at the convent of the Capucins, with the surgeons, to compare their observations. They endeavoured to make this union with the strangers, who uniformly refused it, observing in that a conduct directly opposite to the advice and orders of the celebrated physician for whom they professed so much deference, and whom they assert in their book to have taken for their guide. ${ }^{13}$

The plague of Marseilles gave rise to a large literature to which historians, lawyers, priests, poets and physicians contributed. Bertrand says:

of all classes of writers, the physicians were those who made the press most groan with their effusions. ${ }^{14}$

The most important writings published by physicians were later reprinted in Traité de la Peste. ${ }^{15}$ Professor Deidier's own views on the plague and the experiments he performed are found in a series of letters written to other physicians: in a paper entitled Observations sur les causes de la peste de Marseille et sur la manière dont cette maladie se communique; and in an inaugural lecture to the Medical School at Montpellier. These are printed in Traite de la Peste. An account of some Experiments made with the Bile of Persons dead of the Plague at Marseilles, with what appear'd upon the Dissection of the Bodies; as likewise some Experiments made with the 
Bile of Persons dead of other Diseases was sent to Professor Woodward and communicated by him to the Royal Society. ${ }^{16}$

Like the other physicians from Montpellier, Deidier approached the problems set by the plague with preconceived ideas. All these men were protégés of Chirac and prepared to support his view that the plague of Marseilles was only a malignant fever arising from corrupt humours bred in the body in consequence of irregularities of the season and bad food, that it continued to be propagated by the same means in concurrence with terror, grief and despondency, that it had not been imported from the Levant and that it was not disseminated by contagion.

While waiting at Aix for the party to leave for Marseilles, Deidier sent the following circular letter to the physicians at Marseilles:

$$
\text { Aix, the - Sept. } 1720 .
$$

It is true, Sir, that besides the cruel malady which afflicts your city, the lower people are overwhelmed with famine, and in a state of sedition?

If this be so, how can you exercise your profession?-will you be so obliging as to give me particular information on this subject, that I may know exactly on what I have to calculate? I wish also to be informed what are the remedies you have essayed, and their success. . . . Have you tried, as Sydenham recommends, first to lower the sick extremely by copious bleedings? ... And do not you think it would be advisable to try first bleeding in the foot, even till the patient faint away, giving afterwards a gentle cardiac? ... The sudden deaths in the present case can only arise from a too great fullness of the internal viscera, which brings on gangrenous inflammations. Thus, without regarding the accidents of the disease, or even the state of the pulse, it were desirable to make some trials of this mode of bleeding. Be so good as to inform me how far this method of treatment appears to be successful; and believe me always with the greatest sincerity

\section{Bertrand comments:}

Your most obedient humble servant, Deidier ${ }^{17}$

It will easily be imagined of how much use to the physicians of Marseilles was this advice of the professor. He will soon be changing his opinion himself, when he visits the sick. ${ }^{18}$

It is to Deidier's lasting credit that he did change his opinion: he was the only physician concerned with the plague of Marseilles who did more than rely on clinical experience and post-mortem examinations for his opinion. In his inaugural address to the medical school at Montpellier he says:

I could not see enormous numbers of the inhabitants perish each day without having my heart torn: I set to work to attempt to discover the nature of this fatal disease and above all the nature of its venom; so that if by good luck I succeeded, I should be able to succour the poor afflicted people. ${ }^{19}$

Although the epidemic began to die down towards the end of October 1720 it was not until the beginning of $172 \mathrm{I}$ that Professor Deidier found time to write to his friends about the plague. In a letter to Monsieur Maugue written in January I 72 I he says: 


\section{Raymond Williamson}

For more than two months Marseilles has enjoyed almost perfect calm. Such good order has been re-established that it hardly seems as though the plague has been here. The inhabitants owe this to M. le Chevalier de Langeron, it is only since he took charge that this disease has been brought under control. 20

At first the views Deidier expressed in his letters were similar to those of his Montpellier colleagues and were based on preconceived ideas, clinical experience and post-mortem observations. His experiments on the transmission of plague are first reported in May I 721 and between then and his inaugural lecture in October I 725 his opinions alter, and he finally comes to look upon plague as being epidemic and contagious.

In a letter written before his experiments were begun he describes the symptoms and course of plague and the remedies he has found useful, saying:

I have not thought it necessary here to describe the nature of the disease nor the causes which have produced it, because it does not seem wise to discuss such a hidden matter before explaining all the symptoms, essential and accidental, which require a long discussion. I am satisfied to say what I have seen and what I have done. ${ }^{21}$

Later he expounds the nature of the disease and the symptoms on the basis of the occurrence of a general thickening of the blood which in some sites is so marked as to produce coagulation and arrest of the circulation, this produces changes in the tissues, causing buboes, carbuncles, etc. His reasons for holding this belief are based on post-mortem appearances and on the following clinical observations: the highest pulse is always hard, the pulse is usually feeble and small, on bleeding the blood is found to be thick and sticky and deficient in fluid, bleeding is harmful, on a number of occasions the disease has been preceded by the passing of a large quantity of clear, very limpid urine which has deprived the blood of fluid and allowed it to thicken.

His correspondent, Monsieur Montresse, replied that while accepting coagulation of the blood as an explanation of some of the changes there were others which he thought could only be explained on the basis of alterations in the salts of the blood, bringing about dissolution of its corpuscles. He asked Deidier how he could explain the occurrence of delirium, purple patches and haemorrhages on his coagulation hypothesis.

The following explanation of purple patches illustrates Deidier's conception.

Purple patches appear on the skin of plague patients without producing any marked elevation because they depend on the arrest of blood in very small capillaries below the epidermis which cannot disturb the flow of blood in the adjacent vessels and make them swell. The blood usually extravasates by rupture of the small vessels, it is then enclosed and the extravasation terminates soon by resolution or gangrene. In the first case the redness disappears with resolution of the patches, in the second the patches become black and death soon follows. The blood in the patches does not coagulate but in my opinion the patches form because the blood is already coagulated by the pestilential venom which has entered it. These little capillary vessels rupture by forcing against an obstruction, this would not occur if the blood was dissolved and the corpuscles broken. ${ }^{22}$ 


\section{The Plague of Marseilles}

He uses similar arguments to explain the occurrence of pustules, carbuncles, buboes and haemorrhages from the urinary and intestinal tracts, etc.

In discussing the cause of plague in these early letters Deidier says that the general opinion is that plague was brought to Marseilles from the Levant in Captain Chataud's vessel and was carried into the city by sailors or by merchandise. He does not attach much importance to contagion and is very sceptical about it. Bertrand says:

He is cautious, above all things, not to acknowledge the contagion,-it is an idea too common for him, and he leaves it to more common physicians. ${ }^{23}$

Deidier expresses his opinion as follows:

I believe that scarcity and dearness of food, bad food, horror, disorder and the fear have contributed as much to the cause of this disease as the said vessel. At least one cannot deny that these causes acting together have not produced the disposition in the blood without which the fluids would not coagulate so strongly and so promptly as they do in this case. The nausea, the vomiting which usually precedes the Marseilles fever, and the bulky stools which I have nearly always noticed to be blackish green in colour, do not allow me to doubt that indigestion foments the thickening of the blood in consequence of which all the essential symptoms can be explained. ${ }^{24}$

The idea that the symptoms and signs of plague could be explained on the grounds of a thickening of the blood with local coagulation was challenged by Chicoyneau. He says:

We cannot ally ourselves with those who pretend that the blood of plague patients is always in a state of coagulation and who base their opinion not only on the nature of the accidents above mentioned but also on inspection and opening of corpses, in which they say they have observed vessels dilated and full of thick black blood as appears by what they have printed and taken care to distribute to the public on this question. But it is a notorious fact that the authors of these tracts have never opened any cadaver, nor been present at the opening of any which I have described here and that it is only hearsay that they insist that the blood in plague is thick and black; ...25

During February, March and April I 72 I, Deidier, with the help of Jacques Robert, a doctor of the College of Medicine of Marseilles, and Claude Rimbault, a doctor of medicine of the University of Aix who was in charge of the pharmacy of the hospital in the Jeu de Mail, made a number of experiments which were described in a short paper signed May $1721 .{ }^{26}$

Deidier first describes the post-mortem appearances which he has observed in various cases of plague and says that he has not opened any plague corpse without finding the four cavities of the heart dilated and full of thick, black, clotted blood, and the gall bladder distended and full of black and green bile. These observations have convinced him that the black and green bile is the cause of the thickening of the blood and the consequent engorgement of the heart, followed by death. He then describes chemical experiments he made on the bile. On adding spirit of vitriol to plague bile it always turned a permanent 
grass-green colour, on adding drops of spirit of nitre it turned, transiently, black as ink, and it always turned deep yellow when oil of tarter was added to it par deffailance or with the fixed alkaline salt of tarter dissolved in water. This yellow colour, which resembled that of natural bile, remained stable for months.

Believing that a derangement of the bile was the chief factor concerned in producing the symptoms and lesions of the plague, he wondered if it might contain a pestiferous venom which could communicate plague in the same way that hydrophobia is communicated by the saliva of a mad dog. He says:

We have made several new experiments of which we shall describe the principal and those which seem to us to shed most light on the nature of the plague, and are most likely to lead to its cure. Plague bile poured into a wound made for that purpose in dogs caused them to become sorrowful, melancholic, drowsy and weary; all the animals died on the third or fourth day with definite signs, internal and external, of the true plague, marked by the presence of buboes, carbuncles, and gangrene of the viscera, similar to those in the human corpses from which the bile had been taken. ${ }^{27}$

He then describes other experiments in which one drachm of plague bile was diluted with two ounces of warm fountain water and injected into the jugular vein of some dogs and the crural vein of others. Some dogs died in four hours, some in four days. They all showed the marks of plague. Having described these experiments, Deidier then says:

Being convinced by the three previous observations that bile mixed with the blood always produces plague we wished to know if the pus from plague lesions, the blood or the flesh of plague corpses would produce the same effect; but we had often noticed a dog in the hospital in the Jeu de Mail which followed the surgeons when they went to dress the sick and which used to swallow greedily the corrupted glands and dressings charged with pus which they took off the plague sores, he even licked up the blood that he found spilt on the ground with the said dressings. Also, we had often seen dogs feeding on the flesh of plague corpses without coming to any harm. The above hospital dog had lived in the same way for three months and was always well, gay, brisk, full of play and friendly with all comers. To determine if this dog had a disposition to take the plague like the others we injected into his blood via the crural vein of the right thigh about a drachm of plague bile and he died on the fourth day like the others with a bubo on the wounded thigh on which likewise there were two carbuncles, and the wound gangrened. ...

Because the plague can only be communicated by pestiferous bile mixed with the blood, and because all the dogs we injected died of this disease, it seemed to us that this disease cannot come from infected air as is commonly believed; because of all animals which breathe the same air only man is attacked by it, and although the above observations are certain proof that all dogs are disposed to take the plague, it remains to search for the cause of this epidemic in the foods which are proper to man which are alone capable of deranging the bile rather than the other humours. ${ }^{28}$

Following this, Deidier asserts that cases of plague had occurred in Marseilles before the arrival of Captain Chataud's vessel; of this, Bertrand says:

He discovers that the plague was in Marseilles not only before the month of May, 1720 , when the vessel to which we ascribe our misfortunes arrived, but even in the preceding year 1719. To support this hypothesis, he rummaged our mortuary registers of that year, where he 


\section{The Plague of Marseilles}

asserts to have found that several persons had died of the plague; he likewise made researches in different families by which he discovered, that during the same period many men, women and even children, had shown symptoms of this disease. He gives us a long list of every body who had a boil or a pimple in any part of the body during that year, of the rise, progress, and termination of which he gives a most ample and exact detail. 29

Deidier goes on to say that it is well recognised by physicians that one of the principal causes of derangement of the bile is bad food, of which there had been much in Marseilles before the epidemic. He then proceeds to discuss the vagaries of the weather and their effects on the crops in I719, concluding:

It is to this irregularity of the seasons which we must attribute the constitution of a thickened blood which is gradually disposed to take the plague. While the vice of the bile which has produced it is without doubt the result of repeated indigestions, occasioned by passions of the spirit roused above all by alarms and fears as well as the mixture of corn from the Levant with a third of barley, oats and rye, which the people of Marseilles ate during the four months which preceded the plague. It appears from the injections quoted above that a poraceous bile mixed with what the ancients called atrabile has certainly produced the thickening of the blood, arrest of which, according to us, is the proximate and immediate cause of this dreadful disease. ${ }^{30}$

There is no mention of contagion in the whole of this account; in fact, Deidier emphasizes the fact, that although many post-mortem examinations had to be made to collect the bile and many experiments performed with it, neither he nor his assistants suffered the least inconvenience. This he says:

Clearly proves that the plague cannot be caught from any malignant exhalation spread in the air, or adhering to the fingers or still less to clothing which we did not change. ${ }^{31}$

It was now becoming difficult to get pestiferous bile because deaths from plague in the town were decreasing and if Deidier's experiments had ceased here they would hardly have been worth recalling. However, he managed to obtain more bile and perform more experiments, but not all of those which he had planned. He recorded them in letters to Monsieur Montresse. When he returned to Montpellier he repeated his experiments using bile from patients dying of acute fevers other than plague. The most complete account of his work was sent to Professor Woodward, who communicated it to the Royal Society. ${ }^{32}$ His experiments on the transmission of plague may be summarized as follows:

I. Pestiferous bile poured into wounds made for that purpose in a number of dogs produced symptoms of plague and death in from three to four days with the essential marks of the plague-buboes, carbuncles, and gangrenous inflammation of the viscera.

2. Diluted pestiferous bile injected intravenously into the veins of dogs caused death within a few days with the post-mortem signs of plague.

3. Bile from a dog dying of plague was injected into the blood of a second dog and bile from that dog into a third dog. They all had symptoms of plague and died. Post-mortem examination revealed signs of plague.

4. Two dogs were made to swallow 'a pretty large quantity of Bile taken 


\section{Raymond Williamson}

from the Bodies of Persons dead of the Plague'. They were ill for twenty-four hours but 'recover'd their perfect Health'.

5. Six control experiments performed at Montpellier with the help of a physician, Monsieur Fizes, and two young surgeons, Messrs. Duli and Morel, were negative.

The above forms a series of carefully planned experiments to test the hypothesis that in plague there is a fault in the bile, which hypothesis was based on the observation that in death from plague the gall bladder is distended with thick black and greenish bile. In his third letter to Monsieur Montresse-after speaking of his two colleagues Robert and Rimbault-he says:

I said to these two men that I thought the plague depended on a fault of the bile just as hydrophobia depends on a fault of the saliva. To test this conjecture we began to collect quantities of bile from plague corpses ... we then put it into wounds of dogs, and we injected it into their veins; and all the animals died of the plague..$^{88}$

At first Deidier seemed to be more interested in how and why plague bile differed from normal bile, than he was in the fact that he had transmitted plague. His third and fourth letters to Monsieur Montresse contain much speculation about the changes in the bile and nothing about contagion. He describes his chemical experiments on bile and answers questions put by Monsieur Montresse, who favours the view of Sylvius de la Boë to the effect that changes in salts in the bile produce coagulation and dissolution of the blood which may follow one another or occur at the same time in different subjects, rather than Deidier's view that only thickening and coagulation occur.

Sylvius taught that vinegar was a preservative from the plague and advocated the swallowing each morning of a piece of bread soaked in a spoonful of common vinegar. Deidier says:

If vinegar was the preservative from the plague that this author pretends, then this disease should certainly not have ravaged Marseilles to the extent which it did, for we found on arriving there everybody furnished with a sponge full of this preservative which they popped to the nose at every moment. ${ }^{34}$

He has much more to say about the use of vinegar and concludes that it is of no use as a preservative and no use in treatment.

Deidier begins to consider contagion in his fourth and fifth letters to Monsieur Montresse. He realizes that his experiments only demonstrate the simple fact that plague is transmissible. He says:

When I had at last the opportunity to work on corpses, I examined whether the bile of the plague victims contained the venom of the plague as the saliva of mad dogs contains that of hydrophobia. Although the experiments which I made to that end showed me beyond doubt that plague can be communicated and is transmissible from one subject to another, they did not show how the disease is carried neither the portal of entry. This is a mystery which appears to me to be impenetrable and on which one can only make conjectures. ${ }^{35}$

$$
246
$$


He then compares plague with other diseases, and in discussing syphilis reveals that he has considered the possibility of plague being caused by living organisms, but, unfortunately, he discards this view. He tells us that because mercury destroys all sorts of minute living creatures he believes that the venom of syphilis consists of a species of 'vers vénériens', so:

I at first thought that the plague of Marseilles could depend on another species of pestilential worm which could have been carried from Seyde on Captain Chataud's vessel and afterwards multiplied and spread the plague everywhere. ${ }^{36}$

To test this conjecture he had a mecurial ointment prepared at Aix and persuaded a physician in the infirmary there to have it rubbed into various plague lesions. This treatment was unsuccessful although pushed to salivation. He then learned that a surgeon in Marseilles had tried mercury without success and so, he says: 'I was entirely disabused of my conjecture.' ${ }^{37}$

It seems strange to us that Deidier did not try to transmit plague by injecting pus from buboes. The reason he did not do so was that current theories and some of his own observations had led him to suppose that the venom of plague disappeared when suppuration occurred. He believed that when pestilential bile became concentrated it passed into the intestine to be absorbed by the lacteals and distributed everywhere throughout the body. Where it became concentrated plague lesions developed, but if the lesions suppurated the venom disappeared. He says:

I have constantly observed that when the eruptions of plague begin to suppurate the patients are usually out of danger. Their pus does not contain any pestilential venom which will not soon be destroyed. ${ }^{38}$

His observations that the little dog that ate dressings did not develop plague and that surgeons dressed plague wounds with impunity also strengthened this view, and so he appears to have thought it unnecessary to put the problem to experimental test.

He accepts the view that plague is contagious, but not to the degree that many people think. He recognizes many difficulties in explaining how it is spread, and is driven to assume that some general cause independent of contagion must play a part:

because it is certain that a number of persons have caught it without having had any suspected communication. When we have seen as many as 500 persons fall sick in a day in different parts of the town each shut up in his own house, without any communication with others, is it reasonable to think that so many widely dispersed persons could have had contact with plague patients or carried away their belongings before being shut up? Such must be believed if the disease can be acquired by contagion only. How, after the plague had reached its peak in the town, could it spread to attack at the same time bastides ${ }^{39}$ separated from each other? If the disease was not epidemic but simply contagious, it should always have spread 'de proche en proche' and the bastides nearest to the town should have been infected before the more distant ones which had no commerce with others, but this was not so. 10 


\section{Raymond Williamson}

Many explained this mode of spread as being due to a general infection of the air. Deidier rejects this view and considers that bad nourishment brings about a change in the bile which becomes pestiferous and from these cases plague is propagated. He then says, 'I do not however doubt that plague can occur independently of bad food.'41

Some of the views expressed by Deidier in I 721 at the end of the epidemic are not very clear, especially those on how infection is spread, but his interest in the subject continued and his ideas were clarified by the time he gave his inaugural lecture five years later.

Meanwhile it is of some interest to consider what happened to Professor Deidier and his colleagues from Montpellier when the plague of Marseilles was coming to an end. Messrs. Chicoyneau and Verny with Monsieur Soullier offered their services to the town of Aix where the plague was still severe and they left Marseilles at the end of January I 72 I accompanied by several surgeons and assistants. Deidier stayed in Marseilles to advise Monsieur de Langeron, to examine plague convalescents and declare when they could be considered free from contagion. Towards May:

The freedom of communication daily increased: and the fair sex, once more showing themselves in the streets, banished that frightful solitude which had so long reigned in them. The Course and the Port began to resume their accustomed gaiety, and to be again the resort of the beau-monde. ... .

The malady seemed now so entirely subdued, that the magistrates began to think of returning thanks to the foreign physicians and surgeons, who for a long time had done nothing more than increase the numbers at the Promenade. Passports were demanded for them from Mons. de Roquelaure, commandant of the province of Languedoc. Messrs. Chycoineau, Verny and Soulliers were recalled from Aix, that they might embark with the rest: but as they came from a city less healthy than Marseilles was now, they were only received into the Lazaretto. La Ciotat was the place appointed for the quarantine of these gentlemen. Here they began to preach anew their doctrine with regard to the contagion; but so little credit did it obtain, that they found themselves, notwithstanding, shut up within a close barrier, and excluded from all intercourse with the inhabitants of the town. ${ }^{42}$

At Ciotat an accident occurred which might have had serious consequences. It was described by Monsieur Fournier, a medical student who had accompanied Professor Deidier to Marseilles.

At Ciotat we were housed in a religious house the inhabitants of which had been removed and which was surrounded by guards, although it was a quarter of a league from the town and port.

On entering the monastery we encountered a 'perfume' prepared in the chapel which was so violent that Messieurs Verny and Deidier, a surgeon from Montpellier who was with us and two servants, were immediately seized with such terrible suffocation that they would have died in a few minutes; if, because of the loud cries and the extraordinary hub-bub which we made, the commissioner of the guards had not promptly opened the door. They were very ill for several days in spite of all our assistance. ${ }^{43}$ 


\section{The Plague of Marseilles}

After Ciotat they were detained at Grau de Palaccas near Montpellier. In his fifth, and last, letter to Monsieur Montresse, dated 6 July I 72 I, Deidier says:

For six days we have now been a league and a half from Montpellier between the sea and the lake, beyond all commerce, camping under canvas tents and in huts of straw on the burning sand during the day, very humid during the night and salty night and day. Some soldiers guard us at a distance carrying muskets which they are ready to discharge at any moment to prevent us approaching them as though we were really plague victims. We are fifteen persons, all very well. Twelve masters and three servants. They did not wish us to have those we brought from Provence to serve us during this second quarantine. We have gone through two long and severe storms on the sea in an old boat of Ciotat managed by sailors who do not know the coast and who took three days for what twenty four hours should have been sufficient. On landing we had to bathe naked in the sea, give the sailors our clothes and put on new ones which had been brought for us from Montpellier. After all these precautions they did not wish to receive us at Maguelone for fear that we should infect the harvest which was taking place on the island. The only concession we were able to obtain from the Commissioners of Health who had been sent out from Montpellier and Cette to receive us has been to allow us to send several papers, after they have been soaked in vinegar. . . .44

Another untoward incident occurred before their quarantine was completed. It is described by Fournier:

An unexpected accident occurred on the thirty eighth day of our quarantine at eight o'clock in the evening. A fire broke out in one of our cabins, through the carelessness of the surgeon Galabert. It spread rapidly to four others and they were all burned down in a quarter of an hour in spite of help from the guards and plenty of water available.

The Commandant and the health officers were at once informed of the accident and requested to give us leave to terminate the quarantine a day early, but they could not allow it and it was not until the next day, after having burned a second change of our clothing, that they lead us to the town (Montpellier) in triumph which we had bought at the expense of so much fatigue and danger. ${ }^{45}$

There 'they were received with the acclamations of all the people, with triumphal arches and illuminations'. ${ }^{46}$

Four years after returning from Marseilles, Deidier gave the inaugural address at the School of Medicine in Montpellier and chose as his subject the contagiousness of the plague. ${ }^{47} \mathrm{He}$ says that two of his colleagues had already lectured to the public on this subject:

one against it in a discourse of surpassing eloquence, the other in favour of it in a dissertation in which the spirit of geometry reigned from beginning to end. ${ }^{48}$

\section{Chicoyneau, who was the anti-contagionist, had said:}

Being therefore convinced by experience and long meditation that the plague is neither communicated by touch, nor by the breath and after having carefully weighed all the reasons and observations that it is customary to allege to the contrary, we are fully persuaded, as we have said above, that one cannot understand the nature, nor the causes of this disease, nor how to treat it or prevent it, unless one discards the prejudice in favour of contagion, ...." 


\section{Raymond Williamson}

Chicoyneau believed that plague was a common malignant fever caused chiefly by bad food and that it was always present in all the big towns in Europe, and usually responded well to treatment; it only became gangrenous and incurable and assumed epidemic proportions when people called it the plague and terror of it spread so that the sick were neglected by their friends neighbours and physicians, and public services broke down.

Deidier, in the preamble to his discourse, said:

My object to-day is to weigh carefully the reasons for and against, and adopt or reject them as they seem to me to conform or not with the various events which I have witnessed, convinced that one should not make facts to fit systems but systems to fit facts. ${ }^{\text {so }}$

He goes on to say that it must be admitted that the first epidemic of plague must have been due to general causes such as bad food, bad odours, the dirtiness inseparable from indigence, marshy air or famine and that these causes may still produce it today. He denies that fear is a cause of plague, and speaking of Gerstman's view that plague is neither caused by contagion or general causes but solely by fear which upsets the blood and produces buboes and carbuncles Deidier says, 'Is he awake or does he dream?' 51

Deidier then refers to his own experiments and says that any disease which can be transmitted is certainly contagious and

Anyone who persists in denying that plague is contagious is as prejudiced as the Stoic who when ground in a mortar obstinately maintained that he felt not the least pain. ${ }^{52}$

He then says:

Having clearly proved that plague is contagious it now remains to show how it is communicated, it is not by pestilential atoms in the atmosphere but by close and prolonged contact, comparable in some way to the injections of which I have spoken..$^{53}$

He then explains why he does not believe the cause to consist of widespread pestilential aerial atoms, and says:

It remains, Gentlemen, to explain what I mean by close and prolonged contact which I believe is the only way the contagion of plague is passed on. . . . I mean by this contact, to breathe for a long time, and very near, the burning breath which comes from the mouth of the sick. I mean by this contact, to wear the shirt or sleep in the same bed-clothes as the plague stricken, I mean by this contact to touch one's own sores with hands still carrying infected sweat or blood, as was shown to their cost by two surgeons, one was Morlet of Montpellier, the other a surgeon to the Infirmary, the first had an issue which he dressed without washing his hands, he developed plague and died. The second got an accidental wound with a bistoury and continued in spite of my remonstrances, to treat as usual, buboes and carbuncles, he also caught the plague but was lucky enough to recover; from this one can conclude that contagion of plague is something like that of venereal disease; and as one treats the latter patients without any apprehension of their atmosphere, one can in all confidence administer to the plague stricken, providing one avoids the kind of contact I have described. Simply to approach the sick, to examine their buboes and carbuncles, many experiences have convinced us that that can be done without peril.s4 


\section{REFERENCES}

I. Russell, Patrick, $A$ Treatise of the Plague, London, i79i.

2. Gaffarel, Paul, et de Duranty, M, La Peste de 1720 a Marseille $E$ en France, Paris, I9II.

3. Simpson, W. J., A Treatise on Plague, Cambridge, 1905, p. 237.

4. Bertrand, Mons, A Historical Relation of the Plague at Marseilles in the year 1720 , translated by Anne Plumptre, London, 1805, pp. 97-8.

5. Ibid., p. 99 .

6. Ibid., Appendix 2, p. 354 .

7. Ibid., pp. 104-5.

8. Traité de la Peste, edited by Chicoyneau and Senac, Paris, 1744, p. 480.

9. The History of the Great Plague in London, in the year 1665 , to which is added a Fournal of the Plague at Marseilles, in the year 1720 , London, 1754 , Pp. 352-3.

10. BERTRAND, op. cit., pp. $246-7$.

I1. Journ. of the Plague, p. 359 .

12. BERTRAND, op. cit., p. 247.

13. BERTRAND, op. cit., pp. 248-9.

14. Ibid., p. 265.

15. Traité de la Peste, edited by Chicoyneau and Senac, Paris, 1744.

16. Phil. Trans., 1 722-3, xxxII, 20-32 and 105.

17. BERTRAND, op. cit., pp. I90-1.

18. Ibid., p. I91.

19. Traité de la Peste, pp. 35 I-2.

20. Ibid., p. 480 .

21. Ibid., p. 483 .

22. Ibid., pp. 498-9.

23. BERTRAND, op. cit., p. 280.

24. Traite de la Peste, pp. 467-8.

25. Ibid., p. 343 .

26. 'Observations sur les causes de la peste de Marseilles, et sur la manière dont cette maladie se communique, par M. M. Deidier, Robert et Rimbault,' Traité de la Peste, pp. 20 I-7.

27. Ibid., p. 202.

28. Ibid., pp. 203-4.

29. BERTRAND, op. cit., p. 295.

30. Traité de la Peste, pp. 205-6.

31. Ibid., p. 206.

32. Loc. cit.

33. Traité de la Peste, pp. $50 \mathrm{I}-2$.

34. Ibid., p. 5 Io.

35. Ibid., p. 522.

36. Ibid., p. 522 .

37. Ibid., p. 522 .

38. Ibid., p. 5 19.

39. Bastides were country residences or small estates on the outskirts of the town.

40. Ibid., pp. 525-6.

4I. Ibid., p. 528.

42. BERTRAND, op. cit., pp. 339-4I.

43. Pièces Historiques sur la Peste de Marseille, 2 vols., Marseille, 1820, II, 3-4.

44. Traite de la Peste, pp. 51 7-18.

45. Pieces Historiques, loc. cit., pp. 5-6.

46. Biographie Universelle, Paris, 1857 , vir, 136. 


\section{Raymond Williamson}

47. Traité de la Peste, Discours Ou l'on établie un sentiment particulier sur la contagion de la peste, prononcé d l'overture solemnelle de l'Ecole de Medicine de Montpellier, faite le 22 Octobre 1725 par Monsieur Deidier, pp. 345-58.

48. Traite de la Peste, p. 346 .

49. Ghicoyneau, Françors, Traduction du Discours Latin prononce pour l'overture solemnelle des Ecoles de Medicine, Montpellier, le 26 Octobre de l'annee 1722, Montpellier, 1723, pp. 17-18.

50. Traité de la Peste, p. 346.

51. Ibid., p. 349.

52. Ibid., p. 352 .

53. Ibid., p. 353 .

54. Ibid., pp. 356-7. 